OPEN ACCESS

Edited by:

Jie-Sheng Chen,

Shanghai Jiao Tong University, China

Reviewed by:

Wei Luo,

Tongji University, China

Mataz Alcoutlabi,

The University of Texas Rio Grande

Valley, United States

Chunhai Jiang,

Xiamen University of Technology,

China

*Correspondence:

Hongying Hou

hongyinghou@kmust.edu.cn;

hongyinghou@hotmail.com

Specialty section:

This article was submitted to

Colloidal Materials and Interfaces,

a section of the journal

Frontiers in Materials

Received: 13 February 2019

Accepted: 05 April 2019

Published: 24 April 2019

Citation:

Hou H, Dai Z, Liu X, Yao Y, Yu C and

Li D (2019) Direct and Indirect

Recycling Strategies of Expired

Oxytetracycline for the Anode Material

in Lithium lon Batteries.

Front. Mater. 6:80.

doi: 10.3389/fmats.2019.00080

\section{Direct and Indirect Recycling Strategies of Expired Oxytetracycline for the Anode Material in Lithium Ion Batteries}

\author{
Hongying Hou ${ }^{1 *}$, Zhipeng Dai ${ }^{1}$, Xianxi Liu ${ }^{2}$, Yuan Yao ${ }^{1}$, Chengyi Yu ${ }^{1}$ and Dongdong $\mathrm{Li}^{1}$ \\ ${ }^{1}$ Faculty of Material Science and Engineering, Kunming University of Science and Technology, Kunming, China, ${ }^{2}$ Faculty of \\ Mechanical and Electrical Engineering, Kunming University of Science and Technology, Kunming, China
}

It is well-known that the antibiotics inhibit the wide spread of various infection diseases and guarantee the life safety of many patients. However, various waste antibiotics into the environment also pose the great challenges of the environmental contamination and the ecological poison. Unreasonable disposal of expired antibiotics is one of the main sources of waste antibiotics in the ecological environment. For this reason, in order to focus on the circular economy of such highly refined medical grade chemicals, expired oxytetracycline was recycled for the anode active material in lithium ion batteries (LIBS) by direct and indirect strategies. That is, it was directly used as the anode active material or recycled by two-step carbonization for LIBs anode. Furthermore, the effect of these two strategies on the electrochemical performances was also discussed. Both anode materials showed their individual advantages and high feasibility for LIBs anode. For example, both them delivered the satisfactory Li-storage performances. Additionally, the direct route possessed lower recycling cost and high recovery rate, while the application range of carbon material in the indirect route was broader.

\footnotetext{
Keywords: expired oxytetracycline, recycling, carbon anode, lithium ion batteries, circular economy
}

\section{INTRODUCTION}

The development of the mankind has been accompanied by various infection diseases, that is, various lives in the world have suffered from the threats from various infection diseases. Fortunately, the discovery of the antibiotics in the twentieth century defended these lives against the attacks from various infection diseases owing to broad-spectrum antibacterial activity and easy availability. Therefore, massive antibiotics were produced in large scale for the clinic therapy of the infection diseases, and the annual consumption in the world reached about 100,000-200,000 tons (Kummerer, 2009; Wang et al., 2017). Unfortunately, not all the antibiotics can be completely consumed prior to the validity period. Resultantly, about $40 \%$ antibiotics are inevitably overdue and surplus. As one of important indicators about the safety and the effectiveness of medicines, the validity period can guarantee the medication safety and avoid the occurrence of the medical accidents with very low probability. So once the antibiotics expire, they can't be continually used for the clinical therapy anymore. Currently, these expired antibiotics generally experience the incineration or landfill. However, such treatments will lead to the waste of useful resources as well as the environment pollutions. It is very difficult to eliminate the antibiotics once they flow into 
the natural environment (Wang et al., 2014; Xiong et al., 2017). The antibiotics in the ecological environment would do harm to the creatures and induce the generation of the antibioticresistant bacteria, thus making the treatment of the patients more difficult and increasing the mortality (Yan et al., 2013; Sullivan et al., 2017). Therefore, it is urgent to reasonably recycle the expired antibiotics and effectively prevent from their emission into the environment. In fact, for these highly refined medical grade chemicals, the expiration does not always mean the metamorphism. So it is particularly important to pursue the new strategy to exploit the secondary non-medical value for the alternative applications, thereby reducing their damage to the ecological environment.

Since being commercialized in 1991, lithium ion batteries (LIBs) have been widely applied, and many desirable materials have been investigated for the anode active materials in LIBs, such as carbon, $\mathrm{Si}, \mathrm{Sn}, \mathrm{P}$, alloys, metal oxides, carbonyl compounds, and so on (Ji et al., 2011, 2016; Liang et al., 2012; Agubra et al., 2016, 2017; Zuo et al., 2017; Agrawal et al., 2018). As one kind of common antibiotics with easy availability and broad-spectrum antibacterial activity, oxytetracycline has been widely applied in the clinical therapy since the commercialization in the middle of nineteenth century (Auerbach et al., 2007; Harja and Ciobanu, 2018). Its molecular structure is composed of four fused rigid rings and several functional groups on the rings such as hydroxyl and amino groups, methyl groups, tertiary amine group, and carbonyl groups, as shown in Scheme 1. Such a structure would make the direct recycling route possible. For example, carbonyl group possesses the potential electrochemical Li-storage activity, while the skeleton may guarantee the structural stability during the cyclic lithiation/delithiation (Armand et al., 2009; Schon et al., 2016). Meanwhile, considering that organic oxytetracycline contains the abundant carbon element, it should be a suitable carbon precursor and serve as the anode material in LIBs after carbonization. Seemingly, it may be an interesting attempt to reuse expired oxytetracycline as the anode active material in LIBs via the direct or indirect routes.

As mentioned above, the direct recycling strategy as the anode material mainly depends on the electrochemical Li-storage activity of the functional group within the oxytetracycline. However, not all the organic drugs are active to the electrochemical Li-storage. Alternatively, the indirect strategy can make up for this limitation and play an important role in recycling the expired medicines, because quite a few organic drugs contain rich carbon element and can be indirectly applied as LIBs anode after carbonization. Considering that hydrothermal carbonation may facilitate to form the regular morphology with uniform particles size, it could be used to control the morphology during the carbonization of expired oxytetracycline (Titirici and Antonietti, 2009; Tang et al., 2012; Zhang et al., 2012). However, to the best of our knowledges, the corresponding report is still scarce. Herein, such an attempt was made: both the direct and indirect strategies were adopted to recycle the expired oxytetracycline for the anode active material in LIBs, and the effect of different recycling routes was also compared and discussed.<smiles>CN(C)C1C(O)=C(C(N)=O)C(=O)C2(O)C(O)=C3C(=O)c4c(O)cccc4C(C)(O)C3C(O)C12</smiles>

SCHEME 1 | Chemical structural formula of the oxytetracycline.

\section{EXPERIMENTAL}

\section{The Recycling of Expired Oxytetracycline Tablets}

The expired oxytetracycline tablets (containing more than $90 \mathrm{wt} \%$ of oxytetracycline before expiration) were from the household reserve, and the expiration time was half a year. As shown in Figure 1, these tablets were recycled by direct and indirect routes, respectively. In the case of the direct recycling strategy, the expired oxytetracycline tables were directly downgraded as the anode active material in LIBs after being ground into the powders. For the indirect route, expired oxytetracycline tables were recycled via hydrothermal carbonization and the subsequent pyrolysis. Firstly, $2.3 \mathrm{~g}$ expired oxytetracycline powders were dissolved in $50 \mathrm{~mL} 0.7 \mathrm{wt} \% \mathrm{HCl}$ solution and stirred for $0.5 \mathrm{~h}$. Secondly, the resultant yellow solution was heated at $200^{\circ} \mathrm{C}$ for $5 \mathrm{~h}$ in an autoclave as a result of black suspension. Thirdly, the black solid powders were collected from the black suspension and pyrolysed at $800^{\circ} \mathrm{C}$ for $1 \mathrm{~h}$ in $\mathrm{N}_{2}$ atmosphere. Finally, some black carbon powders were obtained after being cleaned and dried.

\section{Characterization of Microstructure and Morphology}

The microstructure and morphology of the samples were characterized by scanning electron microscopy (SEM) (Quanta 200, FEI, USA), energy dispersive X-ray spectroscopy (EDS) (Apollo, EDAX, USA), Fourier transform infrared (FTIR) spectra (Nicolet iS10, USA), X-ray photoelectron spectroscopy (XPS) (K$\alpha+$, Thermo Fisher, USA) and X-ray diffraction (XRD) (TTRAX III, Riguku, Japan) with $\mathrm{Cu} \mathrm{K} \alpha$ radiation $(\lambda=1.5406 \AA)$ at $40 \mathrm{kV}$ and $10^{\circ} / \mathrm{min}$, respectively.

\section{Electrochemical Measurements}

The electrode slurries were prepared by mixing expired oxytetracycline powders or expired-oxytetracycline-derived carbon powders with acetylene black and polyvinylidene fluoride in mass ratios of 6:3:1 and 8:1:1 in N-methy-2-pyrrolidine, respectively. The anodes were obtained by pasting the slurries onto the single surface of $\mathrm{Cu}$ foils and then vacuum dried at $60^{\circ} \mathrm{C}$ for $12 \mathrm{~h}$, and the corresponding densities of active materials were about 1.2 and $1.5 \mathrm{mg} / \mathrm{cm}^{2}$, respectively. The electrochemical Li-storage performances were tested by assembling CR2025 coin cells with Li foil and Celgard 2,400 film as the counter electrode and the separator, respectively. The electrolyte was $1 \mathrm{M} \mathrm{LiPF}_{6}$ 


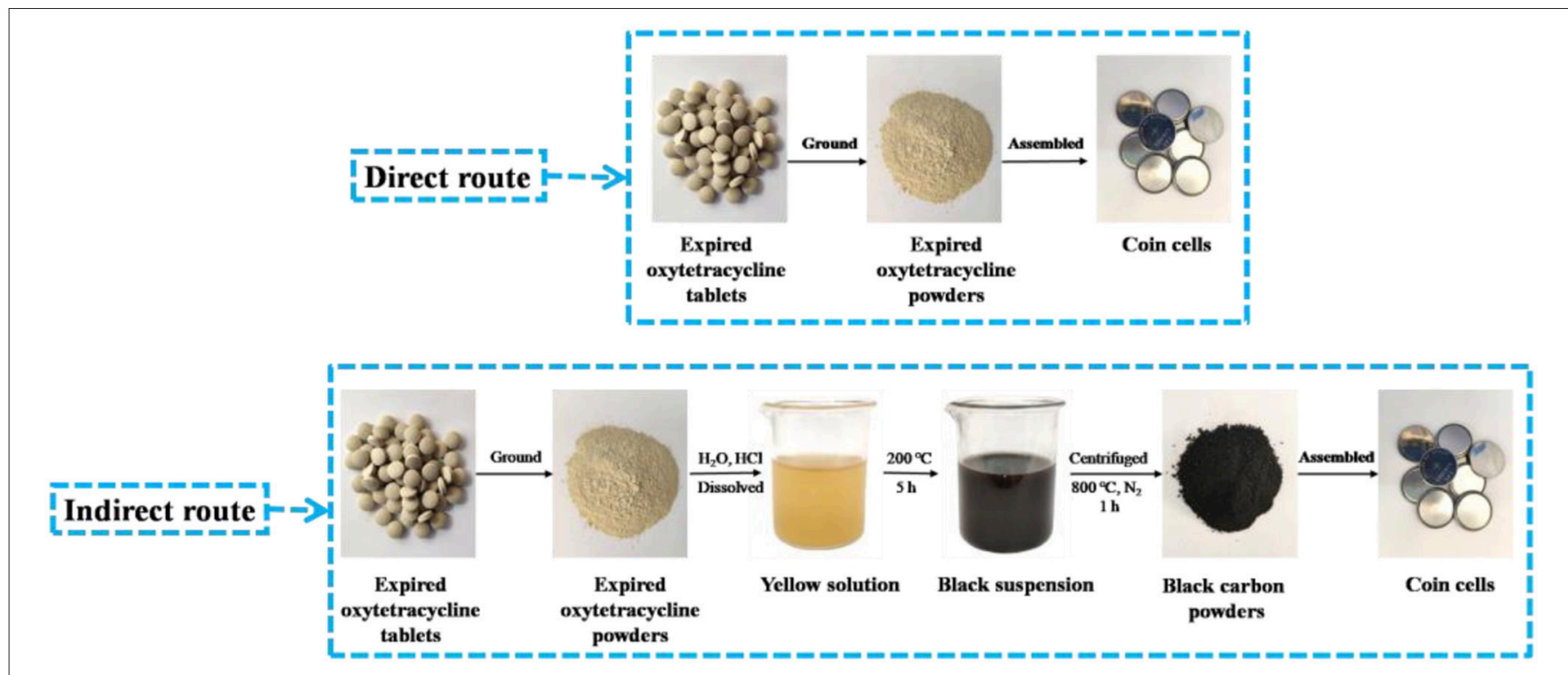

FIGURE 1 | The direct and indirect recycling routes of expired oxytetracycline.

in the mixed ethylene carbonate and diethyl carbonate (1:1 in volume). The voltage ranged from $0.01 \mathrm{~V}$ to $3.0 \mathrm{~V}$ and the current densities were 50,100, 200,400, 800, 1,600, and 2,000 $\mathrm{mA} / \mathrm{g}$, respectively. Furthermore, cyclic voltammetry $(\mathrm{CV})$ was performed on an electrochemical workstation (Parstat 4,000, Princeton Applied Research, USA) at $0.2,0.4,0.6,0.8$, and $1.0 \mathrm{mV} / \mathrm{s}$ between 0.01 and $3.0 \mathrm{~V}$, and alternative current (AC) impedance was also measured from $0.01 \mathrm{~Hz}$ to $10^{2} \mathrm{kHz}$ with $10 \mathrm{mV}$ amplitude at open circuit voltage of $1.0 \mathrm{~V}$.

\section{RESULTS AND DISCUSSION SEM-EDS}

SEM images and EDS spectra of the expired oxytetracycline powders and the expired-oxytetracycline-derived carbon powders were shown in Figure 2. Prior to two-step carbonization, expired oxytetracycline powders manifested the morphology of irregular microparticles with the diameter of $5.5-11.9 \mu \mathrm{m}$, and many smaller particles attached onto the surface of larger ones (in Figures 2A,B). Such multi-scale particles may be beneficial for the large electrode/electrolyte interface area and the ionic diffusion. According to EDS spectrum in Figure 2C, the main elements in the expired oxytetracycline remained $\mathrm{C}, \mathrm{N}$, and $\mathrm{O}$, coinciding with the chemical element composition of oxytetracycline. To be different, after two-step carbonization, the expired-oxytetracycline-derived carbon powders appeared as many regular microspheres with the diameter from about $2.0 \mu \mathrm{m}$ to hundreds of nanometers, in which some smaller spheres dispersed on the surface or among the gaps of larger microspheres (in Figures 2D,E). Only C and $\mathrm{O}$ elements were detected in EDS spectrum in Figure 2F. Compared with EDS spectrum of the expired oxytetracycline, the peak of $\mathrm{C}$ element became stronger, while the peak of $\mathrm{O}$ element became weaker, and the signal peak of $\mathrm{N}$ element even disappeared, indicating high carbonization degree of expired oxytetracycline.

\section{FTIR Analysis}

In order to gain the insight into the micro-structure of the samples, FTIR spectra were also recorded, as shown in Figure 3. In the case of expired oxytetracycline, the signal peaks were sharp and ample. In detail, one peak at $3,479 \mathrm{~cm}^{-1}$ could be ascribed to the stretching vibration of $\mathrm{O}-\mathrm{H}$ bond, while three peaks at 1,395 , 1,315 , and $678 \mathrm{~cm}^{-1}$ could be assigned to the bending vibration of O-H bond (Jin et al., 2016; Hou et al., 2018a). One peak at $3,372 \mathrm{~cm}^{-1}$ resulted from the stretching vibration of $\mathrm{N}-\mathrm{H}$ bond, and two peaks at 1,245 and $781 \mathrm{~cm}^{-1}$ were due to the bending vibration of $\mathrm{N}-\mathrm{H}$ bond (Jin et al., 2016; Hou et al., 2018a). Three peaks at $1,650,1,622$, and $1,590 \mathrm{~cm}^{-1}$ were attributed to the stretching vibrations of $\mathrm{C}=\mathrm{O}$ bonds on the amide and the rings (Aristilde et al., 2010; Mahamallik et al., 2015). Two peaks at 1,520 and $1,462 \mathrm{~cm}^{-1}$ were ascribed to the stretching vibrations of $\mathrm{C}=\mathrm{C}$ bond (Hou et al., 2018a). In addition, one peak at $3,082 \mathrm{~cm}^{-1}$ was indexed to the stretching vibration of $\mathrm{C}-\mathrm{H}$ bond, and three peaks at 937,861 , and $839 \mathrm{~cm}^{-1}$ were due to the bending vibration of $\mathrm{C}-\mathrm{H}$ bond (Hou et al., 2018a). Furthermore, three peaks at about $1,125,1,182$, and $1,010 \mathrm{~cm}^{-1}$ corresponded to the stretching vibrations of $\mathrm{C}-\mathrm{N}$ bond, $\mathrm{C}-\mathrm{O}$ bond, and C-C bond, respectively (Aristilde et al., 2010; Orellana et al., 2010). Seemingly, FTIR spectrum analysis indicated that the main structure in the expired oxytetracycline didn't significantly change. After two-step carbonization, most of the signal peaks disappeared, and only three broad peaks remained at 3,435, 1,618, and $1,060 \mathrm{~cm}^{-1}$, corresponding to the stretching vibrations of $\mathrm{O}-\mathrm{H}$ bond, $\mathrm{C}=\mathrm{O}$ bond and $\mathrm{C}-\mathrm{C} / \mathrm{C}-\mathrm{O}$ bonds, respectively ( $\mathrm{Hou}$ et al., 2018b). FTIR result indicated that small amount of residual O-containing functional groups remained even after two-step carbonization, in according with EDS spectrum. 

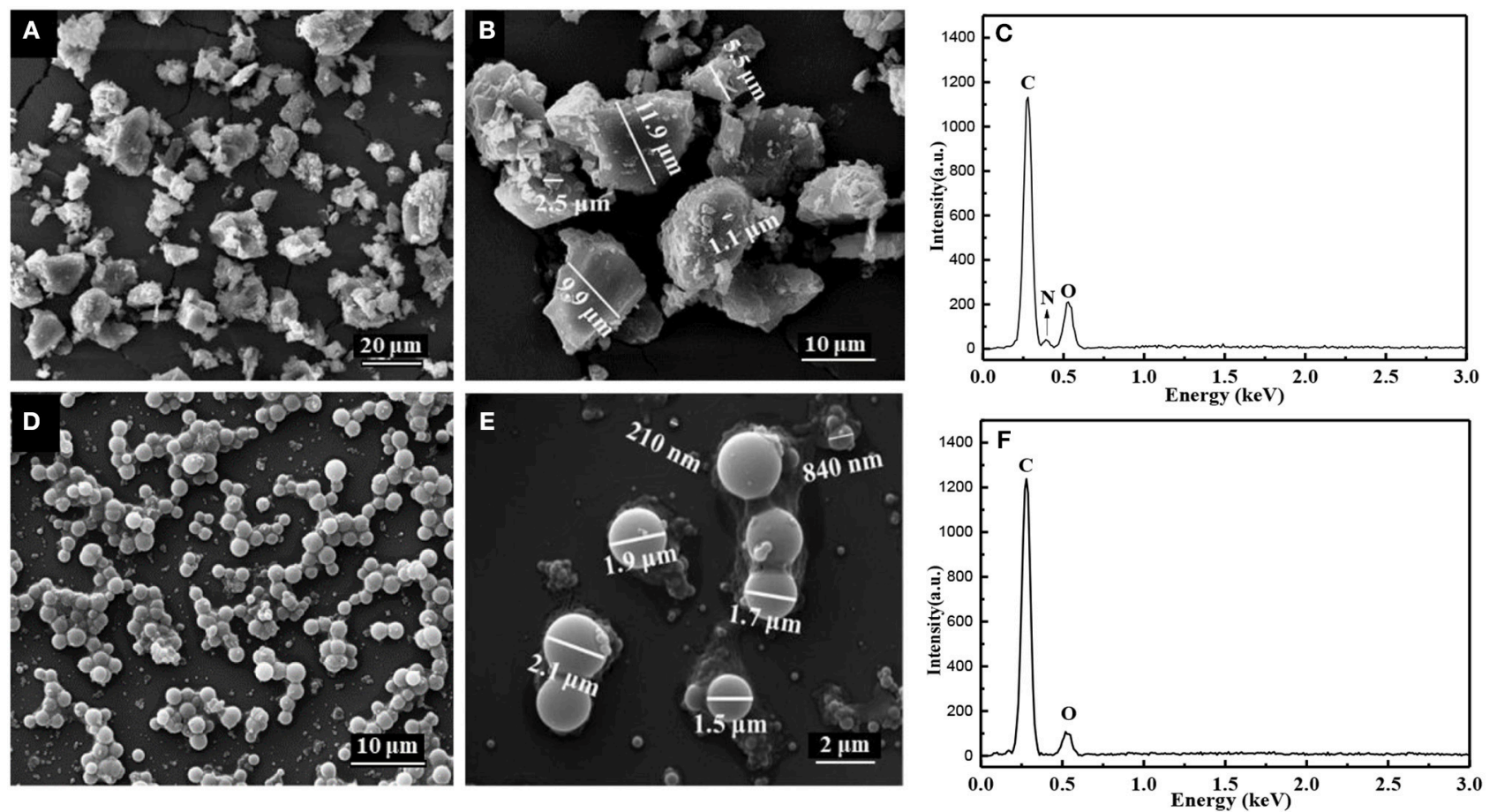

FIGURE 2 | SEM images of (A,B) expired oxytetracycline powders and (D,E) expired-oxytetracycline-derived carbon powders, and EDS spectra of (C) expired oxytetracycline powders and (F) expired-oxytetracycline-derived carbon powders.

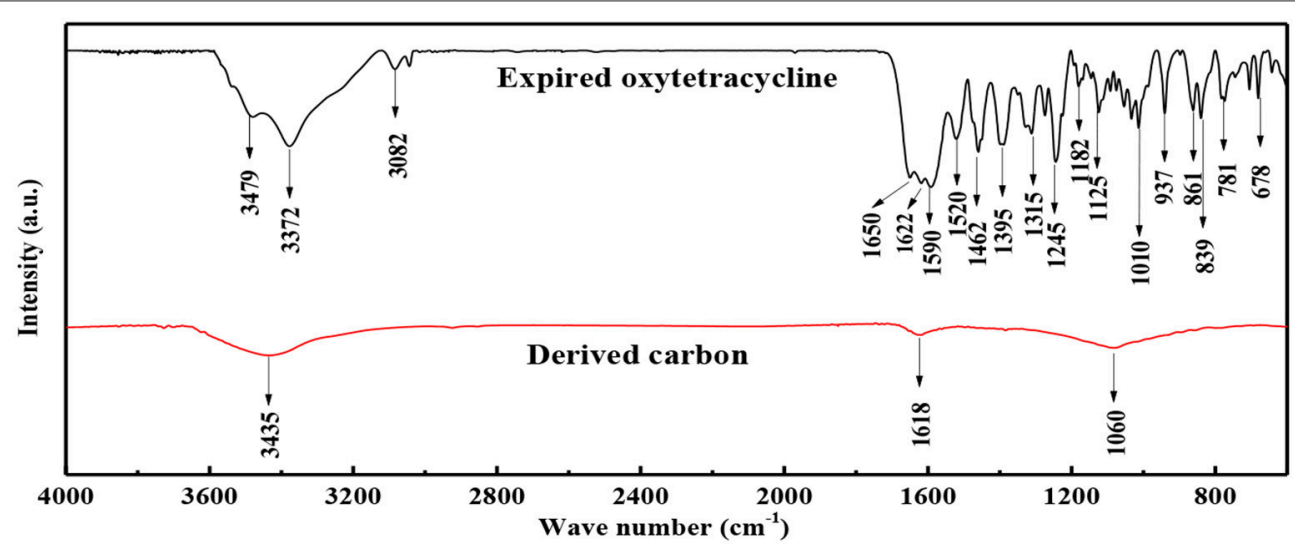

FIGURE 3 | FTIR spectra of expired oxytetracycline and expired-oxytetracycline-derived carbon powders.

\section{XPS Analysis}

The binding states of chemical elements in the samples were further studied by XPS technology, as shown in Figure 4. In the wide scan spectrum of expired oxytetracycline, the signal peaks at about 285, 399, and $533 \mathrm{eV}$ were indexed to $\mathrm{C} 1 \mathrm{~s}, \mathrm{~N}$ $1 \mathrm{~s}$, and $\mathrm{O} 1 \mathrm{~s}$, respectively (Figure 4A). After carbonization, only two signal peaks corresponding to $\mathrm{C} 1 \mathrm{~s}$ and $\mathrm{O} 1 \mathrm{~s}$ still appeared, in which $\mathrm{C}$ 1s peak became stronger, while $\mathrm{O}$ 1s peak became much weaker and $\mathrm{N}$ 1s peak was even absent. Such changes again confirmed the carbonization of expired oxytetracycline, which was consistent with EDS results. Furthermore, these signal peaks can be deconvoluted. In detail, C 1s peak of expired oxytetracycline could be further deconvoluted into four peaks at $284.8,285.4,286.4$, and $287.9 \mathrm{eV}$, which were assigned to C-C/C$\mathrm{H}, \mathrm{C}=\mathrm{C}, \mathrm{C}-\mathrm{O} / \mathrm{C}-\mathrm{N}$ and $\mathrm{C}=\mathrm{O}$ bonds, respectively (Figure $4 \mathrm{~B}$ ). $\mathrm{N}$ 1s spectrum was divided into two peaks at 399.2 and $401.4 \mathrm{eV}$, corresponding to C-N and N-H bonds, respectively (Figure 4C). $\mathrm{O}$ 1s spectrum in Figure 4D was fitted into three peaks at 530.8, 531.7, and $532.7 \mathrm{eV}$, which could be ascribed to $\mathrm{O}-\mathrm{H}, \mathrm{C}=\mathrm{O}$ and $\mathrm{C}-\mathrm{O}$ bonds (Hou et al., 2018a). After carbonization, only three peaks at $284.8 \mathrm{eV}$ (C-C bond), $286.4 \mathrm{eV}$ (C-O bond), and $287.9 \mathrm{eV}$ ( $\mathrm{C}=\mathrm{O}$ bond) were detected in $\mathrm{C} 1 \mathrm{~s}$ spectrum, and the 

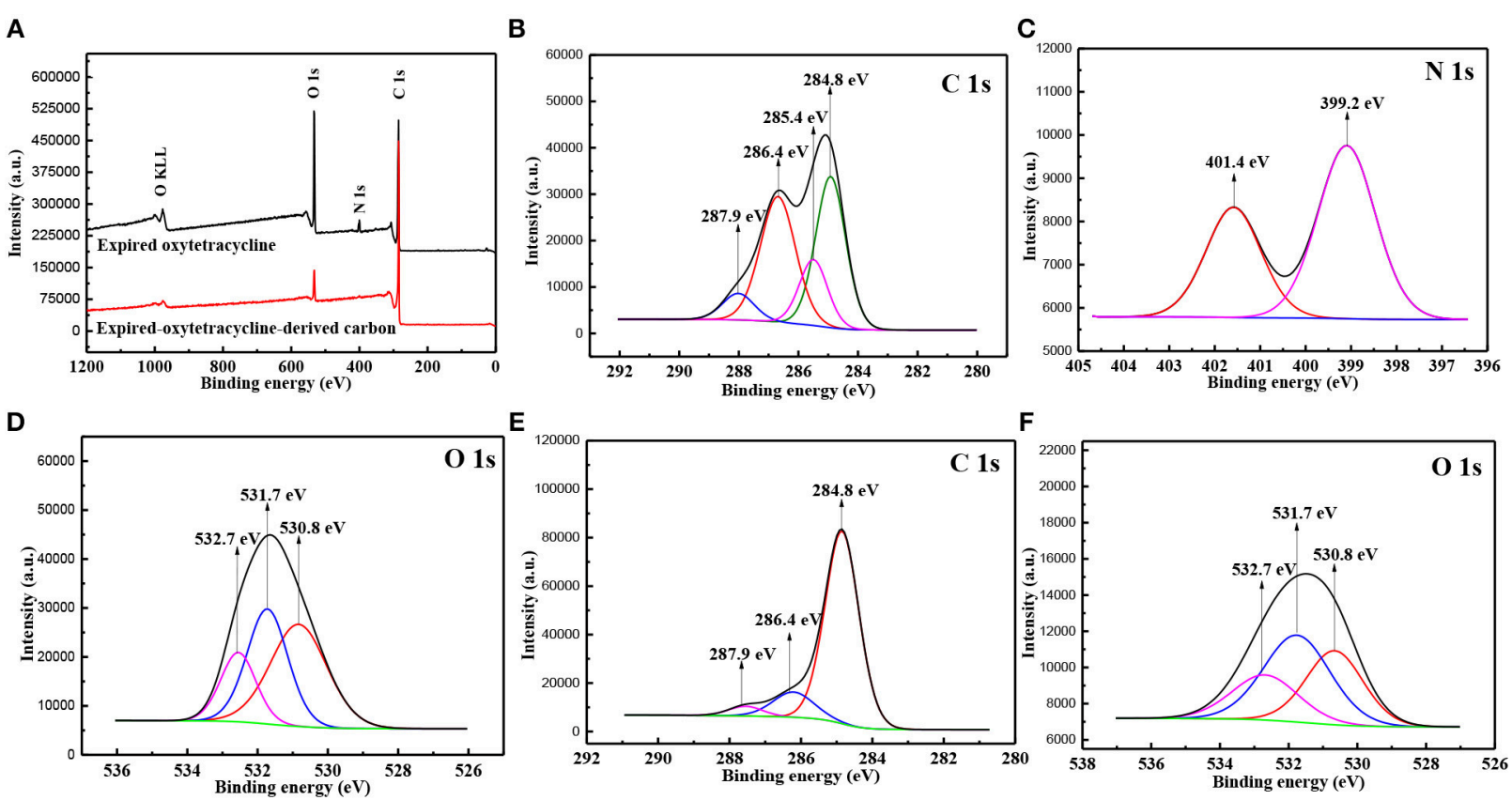

FIGURE 4 | The wide scan XPS spectra (A) of expired oxytetracycline and its derived carbon powders, spectra of (B) $\mathrm{C} 1 \mathrm{~s},(\mathbf{C}) \mathrm{N} 1 \mathrm{~s}$ and (D) $\mathrm{O}$ 1s in expired oxytetracycline, and spectra of (E) C 1s, (F) O 1s in expired-oxytetracycline-derived carbon.
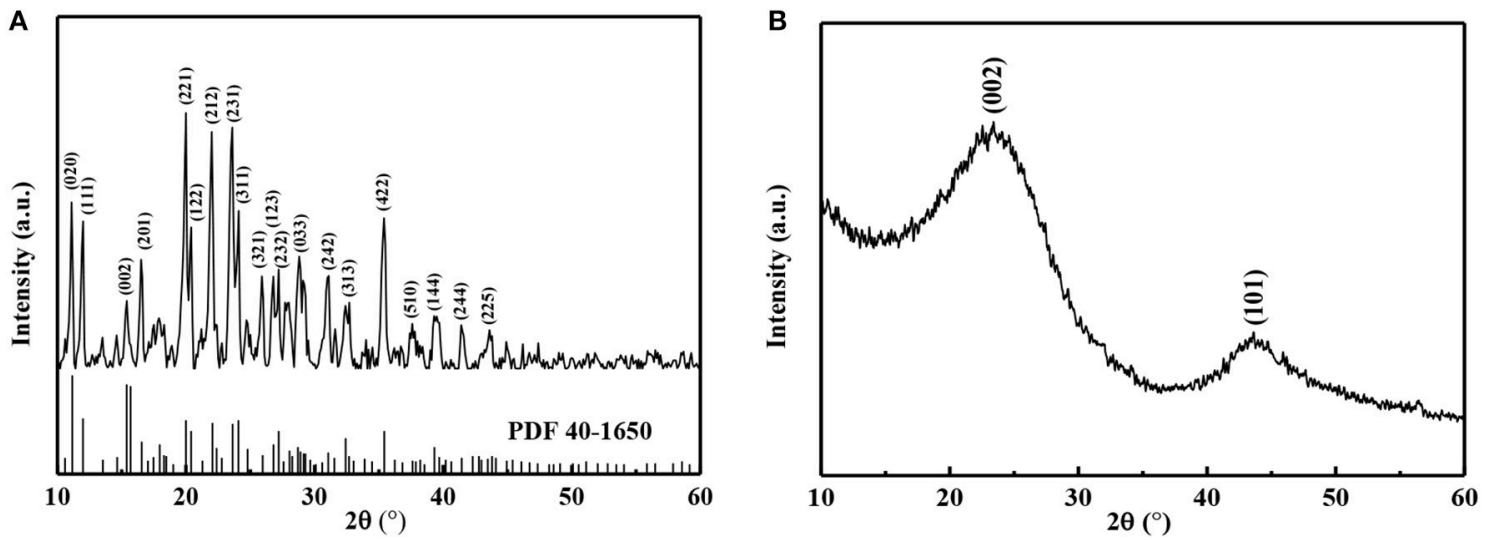

FIGURE 5 | XRD patterns of (A) expired oxytetracycline and (B) expired-oxytetracycline-derived carbon powders.

peak at $285.4 \mathrm{eV}$ corresponding to $\mathrm{C}=\mathrm{C}$ bond disappeared, as shown in Figure 4E. O 1s spectrum in Figure 4F could be also deconvoluted into three peaks similar to the results in Figure 4D, except that the peak intensities became weaker. Obviously, the binding states of chemical elements within two samples were further verified by XPS spectra, in good agreement with EDS and FTIR analysis.

\section{XRD Analysis}

$\mathrm{XRD}$ patterns of two samples were recorded, as shown in Figure 5. In the case of XRD pattern of expired oxytetracycline powders, many sharp diffraction peaks were detected, indicating highly crystal structure of the oxytetracycline due to its orderly molecular structure with four linearly annulated rigid sixmembered rings (in Figure 5A) (Stezowski, 1976; Toro et al., 2007). According to the standard JCPDS card (No. 40-1650), these diffraction peaks at $2 \theta=11.1^{\circ}, 11.9^{\circ}, 15.4^{\circ}, 16.6^{\circ}, 20.0^{\circ}$, $20.4^{\circ}, 22.1^{\circ}, 23.6^{\circ}, 24.1^{\circ}, 25.9^{\circ}, 26.8^{\circ}, 27.2^{\circ}, 28.7^{\circ}, 31.1^{\circ}, 32.7^{\circ}$, $35.4^{\circ}, 37.6^{\circ}, 39.3^{\circ}, 41.4^{\circ}$ and $43.5^{\circ}$ could be assigned to the crystal planes (020), (111), (002), (201), (221), (122), (212), (231), (311), (321), (123), (232), (033), (242), (313), (422), (510), (144), (244), and (225) of the oxytetracycline with $P 2{ }_{1} 2_{1} 2_{1}$ space group. As for XRD pattern of expired-oxytetracycline-derived carbon powders (Figure 5B), two classic diffraction peaks were observed at $2 \theta=23^{\circ}$ and $43^{\circ}$, corresponding to the reflections of (002) crystal plane of parallel-stacked graphene sheets and 

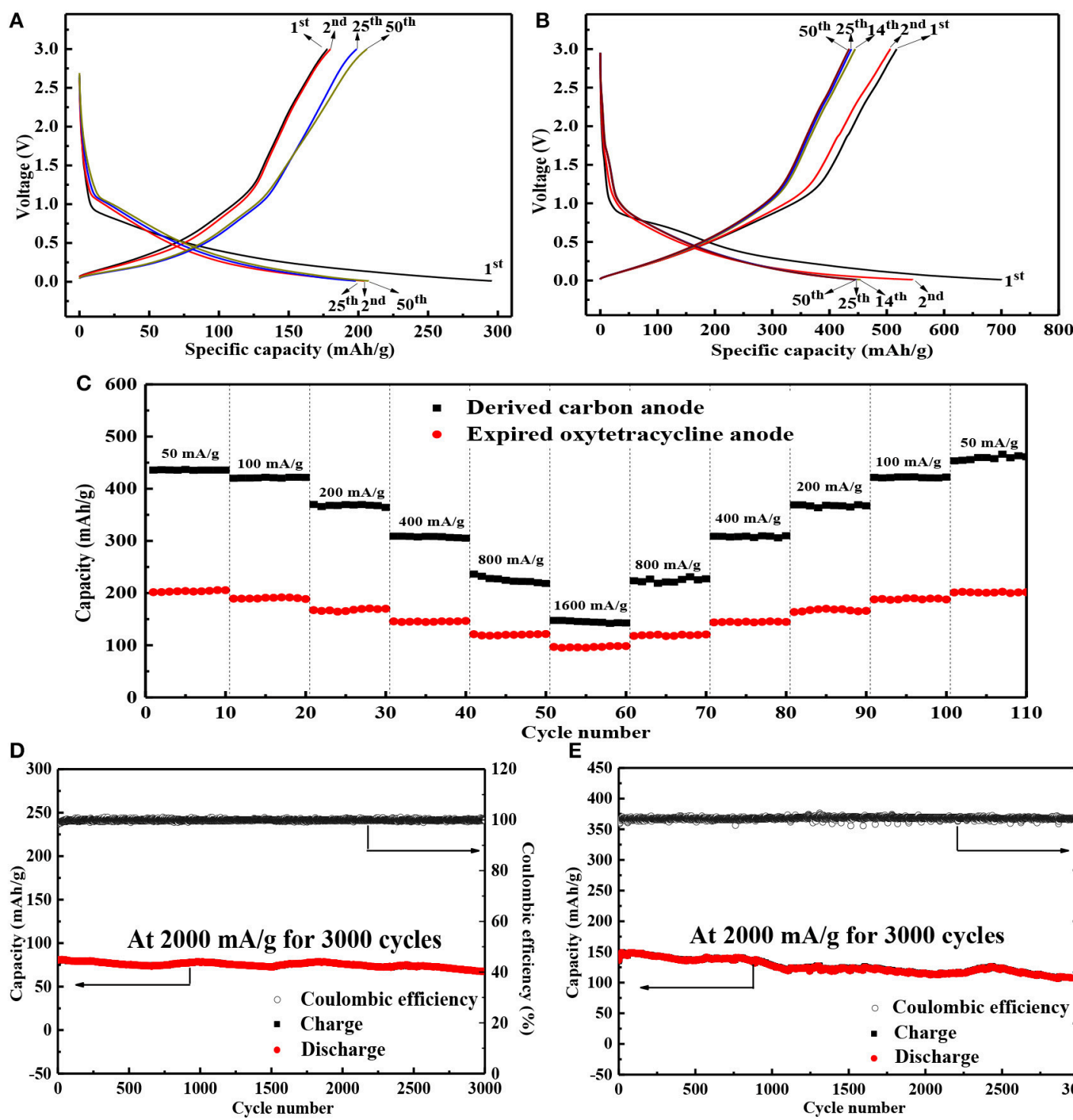

E

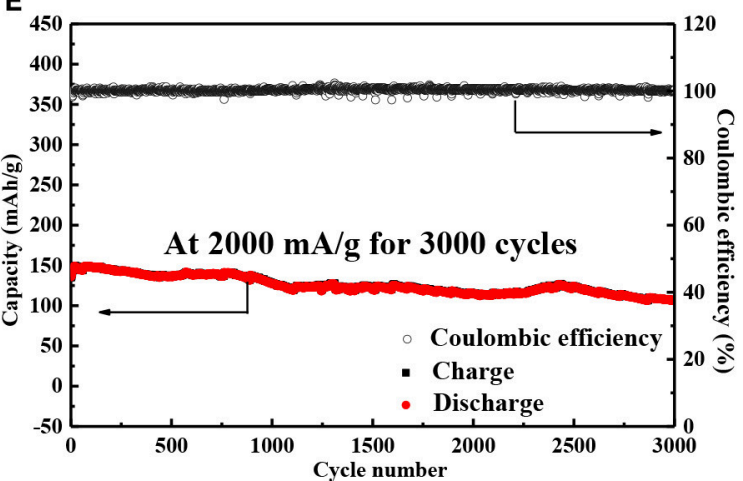

FIGURE 6 | Representative charge/discharge profiles of (A) expired oxytetracycline anode and (B) expired-oxytetracycline-derived carbon anode at 50 mA/g, (C) the rate performances of both anodes and the cyclic performances of (D) expired oxytetracycline anode and (E) expired-oxytetracycline-derived carbon anode.

(101) crystal plane of $\mathrm{sp}^{2}$ carbon with the honeycomb structure, respectively (Han et al., 2014; Wu et al., 2016). Additionally, these two diffraction peaks were broad and weak, indicating amorphous structure.

\section{Electrochemical Performances Charge/Discharge Performances}

When the expired oxytetracycline was directly downgraded as the anode active material in LIBs, the initial and second specific charge/discharge capacities were 177.8/295.8 and 180.0/204.4 $\mathrm{mAh} / \mathrm{g}$, respectively, as shown in Figure 6A. The initial Coulombic efficiency (ICE) and the initial irreversible discharge capacity loss can be calculated as 60.1 and 30.9\%, which may be due to the decomposition of the electrolyte and the formation of solid electrolyte interface (SEI) film on the electrode surface during the initial discharging (Armand et al., 2009; Sun et al., 2016). Subsequently, the discharge specific capacity stably maintained at $207.4 \mathrm{mAh} / \mathrm{g}$ and the Coulombic efficiency increased above $99.0 \%$, indicating high reversibility and feasibility of the expired oxytetracycline anode. After twostep carbonization, the initial and second charge/discharge capacities of expired-oxytetracycline-derived carbon anode were $517.4 / 700.2$ and 506.1/545.0 $\mathrm{mAh} / \mathrm{g}$, respectively (Figure 6B). The corresponding ICE and the initial irreversible discharge capacity loss were 73.9 and $22.2 \%$, respectively, mainly due to the formation of SEI film and the irreversible $\mathrm{Li}^{+}$ insertion/deinsertion in the spaces of carbon anode during the initial discharge (Elizabeth et al., 2016; Zuniga et al., 2016; Huang et al., 2018). Subsequently, the electrochemical reaction gradually tended to be stable. The profiles almost overlapped 
TABLE 1 | The comparison of performances of expired oxytetracycline with other analogous organic anode materials in literatures.

\begin{tabular}{lcc} 
Anode materials & $\begin{array}{c}\text { Initial discharge capacity } \\
\text { (mAh/g), ICE }\end{array}$ & $\begin{array}{c}\text { Capacity (mAh/g) @ current } \\
\text { density (mA/g) for cycles }\end{array}$ \\
\hline Expired-oxytetracycline & $296,60 \%$ & $207 @ 50$ for 50 \\
Li terephthalate & $236,66 \%$ & 85 @ 15 for 50 \\
Tetralithium 2,5-dihydroxyterephthalic acid & $358,71 \%$ & $232 @ 24$ for 50 \\
Dilithium benzenediacrylate & $246,42 \%$ & 170 @ 12 for 20
\end{tabular}

TABLE 2 | The comparison of performances of expired-oxytetracycline-derived carbon with those of other precursors-based carbon anode in literatures.

\begin{tabular}{|c|c|c|c|}
\hline Carbon matrix precursors & $\begin{array}{l}\text { Initial discharge capacity } \\
\text { (mAh/g), ICE }\end{array}$ & $\begin{array}{l}\text { Capacity }(m A h / g) @ \text { current } \\
\text { density }(m A / g) \text { for cycles }\end{array}$ & Literatures \\
\hline Expired-oxytetracycline & $700,74 \%$ & $450 @ 50$ for 50 & This work \\
\hline Sucrose & $906,52 \%$ & $315 @ 50$ for 100 & Agrawal et al., 2018 \\
\hline Rice husk & $789,51 \%$ & $403 @ 75$ for 100 & Wang et al., 2013a \\
\hline Sugarcane bagasse & $560,45 \%$ & $310 @ 200$ for 100 & Matsubara et al., 2010 \\
\hline
\end{tabular}
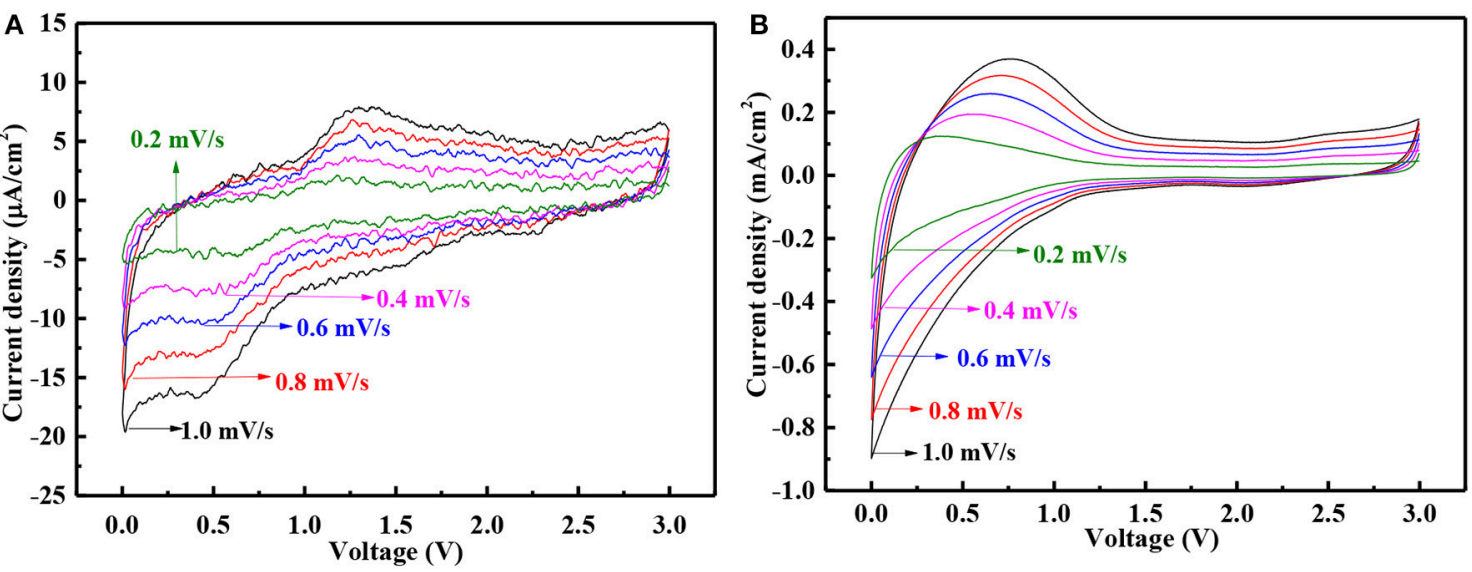

FIGURE 7 | CV curves at different scanning rates of (A) expired oxytetracycline anode and (B) expired-oxytetracycline-derived carbon anode.
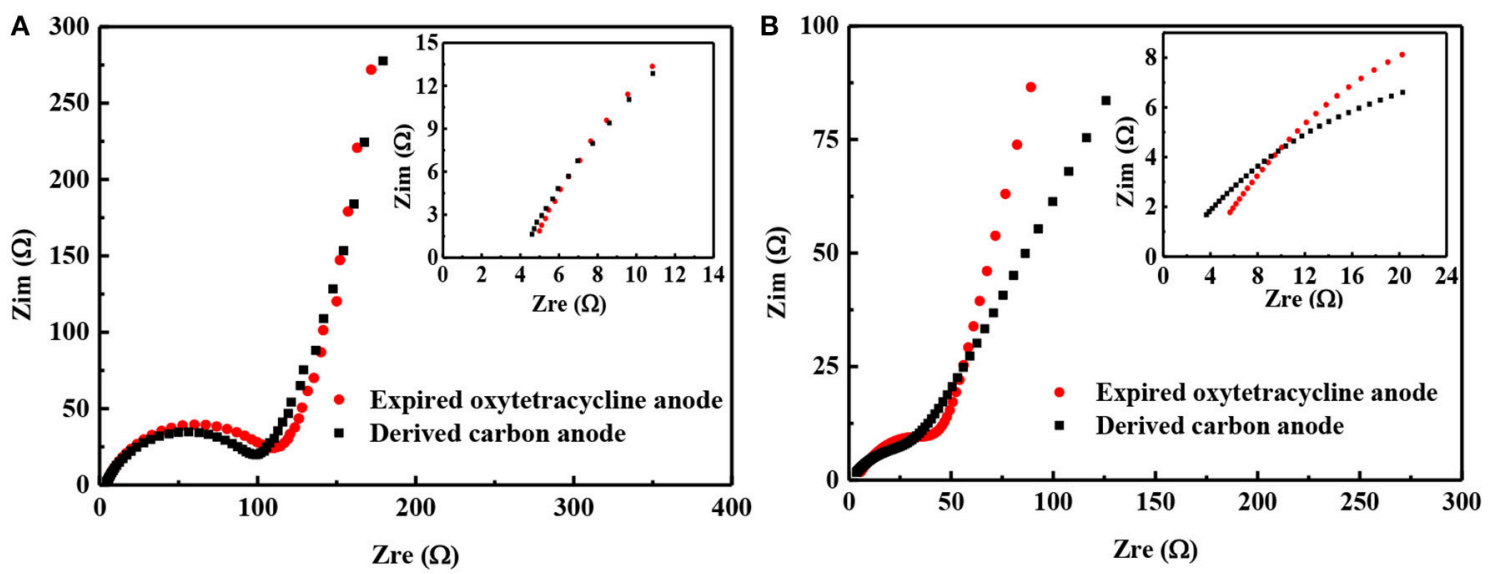

FIGURE 8 | Nyquist plots of two anodes (A) before and (B) after 500 cycles. 
each other from the 14th cycle and the discharge capacities stabilized at $450.3 \mathrm{mAh} / \mathrm{g}$. At the same time, Coulombic efficiency also increased above $97.5 \%$, implying high reversibility of the expired-oxytetracycline-derived carbon anode.

Additionally, both anodes also delivered high rate performances, as shown in Figure 6C. For example, when the expired oxytetracycline anode was cycled at the different current densities of $50,100,200,400,800$, and $1,600 \mathrm{~mA} / \mathrm{g}$, respectively, the corresponding average reversible specific capacities were $207.4,188.5,166.9,144.5,119.1$, and $96.7 \mathrm{mAh} / \mathrm{g}$; while those of the expired-oxytetracycline-derived carbon anode were about 450.3, 421.1, 367.9, 307.7, 225.3, and $144.8 \mathrm{mAh} / \mathrm{g}$, respectively. With the stepwise decrease of the current density, all the reversible discharge capacities could rapidly restore, demonstrating high tolerance to the large current changes. Moreover, both anodes also exhibited stable cyclic performances even at 2,000 mA/g for 3,000 cycles, as shown in Figures 6D,E. In detail, the expired oxytetracycline and expired-oxytetracyclinederived carbon anodes delivered average discharge capacities of 75.1 and $125.3 \mathrm{mAh} / \mathrm{g}$. Meanwhile, the Coulombic efficiency of both anodes could maintain at about $100 \%$ during the long-term cycling. Seemingly, both the direct and indirect recycling routes were feasible during the reutilization of expired oxytetracycline. The electrochemical Li-storage performances of expired oxytetracycline anode in the direct strategy were slightly lower than those of carbon anode from the indirect route, but the electrochemical Li-storage capacity was comparable with those of other similar organic anodes in literatures, as listed in Table 1; moreover, this recycling strategy was simpler and cheaper, and the recovery was higher (close to 100\%). On the other hand, although the indirect route was relatively complicated and expensive, the resultant carbon material possessed wider application range, and its Li-storage performances were also comparable with those of other precursors-based carbon anodes in literatures (Table 2). In a word, both recycling strategies possessed their individual advantages.

\section{Curves and AC Impedance}

In order to further explore the electrochemical reaction mechanism during the charge/discharge, CV curves of two anodes were recorded at different scanning rates, as shown in Figures 7A,B. In the case of expired oxytetracycline anode, one couple of redox peaks were detected at 0.5 and $1.2 \mathrm{~V}$, corresponding to the revisable lithiation/delithiation of $\mathrm{C}=\mathrm{O}$ group, respectively. The possible electrochemical reaction mechanism can be depicted as the following formula (1) (Hou et al., 2018a). Likewise, one couple of redox peaks were also detected in the CV curves of the expired-oxytetracyclinederived carbon anode, but these two peaks appeared at 0 and $0.5 \mathrm{~V}$ respectively. In the case of Li-storage mechanism of carbon anode, $\mathrm{Li}^{+}$can reversibly intercalate into and deintercalate from the interspaces, so this couple of redox peaks should be attributed to $\mathrm{Li}^{+}$insertion/deinsertion in carbon anode structure (Liu et al., 1996; Hou et al., 2018b). With the increase of the scanning rate, all of the peaks became stronger and the peak interval gradually increased. Additionally, compared to the expired oxytetracycline anode, the expiredoxytetracycline-derived carbon anode displayed higher peak current at the same scanning rate possibly attributed to its higher electrical conductivity.

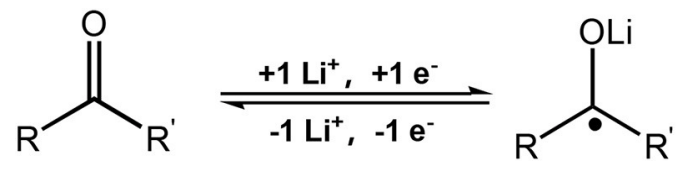

Finally, the electrochemical impedances of both anodes were also measured before and after 500 cycles. Before cycling, the internal resistance $\left(R_{\mathrm{s}}\right)$ and the charge transfer resistance $\left(R_{\mathrm{ct}}\right)$ of expired-oxytetracycline anode can be estimated as 4.5 and $103.1 \Omega$, respectively, higher than 4.3 and $94.3 \Omega$ of expired oxytetracycline-derived carbon anode, as shown in Figure 8A, (Duan et al., 2016). Higher electrical conductivity, smaller particle size and more regular micro-sphere morphology of the expired-oxytetracycline-derived carbon may be responsible for this difference. After cycling, $R_{\mathrm{s}}$ and $R_{\mathrm{ct}}$ of expired oxytetracycline anode decreased to 3.2 and $52.1 \Omega$, while those of expired-oxytetracycline-derived carbon anode also decreased to 2.3 and $39.8 \Omega$, respectively, possibly attributed to gradually activation of the anode during the cycling, as shown in the Figure 8B (Sun et al., 2018).

\section{CONCLUSIONS}

In summary, expired oxytetracycline was recycled for LIBs anode active materials by direct and indirect strategies, respectively. The direct strategy may be limited by the functional group with electrochemical Li-storage activity, but the simplicity, high recovery and low cost were greatly impressed. The indirect strategy need two-step carbonization with high cost and energy consumption, but it was suitable for almost all the expired organic carbon-containing waste drugs, and the resultant carbon material can be applied in more fields such as supercapacitor, LIBs, catalyst support, adsorbent and so on. Seemingly, both routes possessed their individual merits, providing the new strategies to reutilize highly refined medical grade chemicals and delaying the submission of these chemicals into the waste streams.

\section{AUTHOR CONTRIBUTIONS}

$\mathrm{HH}$ : design experiments and write manuscript; ZD: complete major experiments and analysis data; XL: provide theoretical support; YY, CY, and DL: provide help to complete the experiment.

\section{ACKNOWLEDGMENTS}

This work was financially supported by the National Natural Science Foundations of China (Grant No. 51566006 and 51363011), the 46th Scientific Research Foundation for the Returned Overseas Chinese Scholars, State Education Ministry in China (6488-20130039), the 19th Young Academic and Technical Leaders of Yunnan Province (1097-10978240), the Program of High-level Introduced Talent of Yunnan Province (10978125) and the Project of Key Discipline (14078232 and 14078311). 


\section{REFERENCES}

Agrawal, A., Biswas, K., Srivastava, S., and Ghosh, S. (2018). Effect of Ndoping on hard carbon nano-balls as anode for Li-ion battery: improved hydrothermal synthesis and volume expansion study. J. Solid State Electrochem. 22, 3443-3455. doi: 10.1007/s10008-018-4044-6

Agubra, V., Zuniga, L., Flores, D., Campos, H., Villarreal, J., and Alcoutlabi, M. (2017). A comparative study on the performance of binary $\mathrm{SnO}_{2} / \mathrm{NiO} / \mathrm{C}$ and $\mathrm{Sn} / \mathrm{C}$ composite nanofibers as alternative anode materials for lithium ion batteries. Electrochim. Acta 224, 608-621. doi: 10.1016/j.electacta. 2016.12.054

Agubra, V., Zuniga, L., Flores, D., Villarreal, J., and Alcoutlabi, M. (2016). Composite nanofibers as advanced materials for $\mathrm{Li}$-ion, $\mathrm{Li}-\mathrm{O}_{2}$ and Li-S batteries. Electrochim. Acta 192, 529-550. doi: 10.1016/j.electacta. 2016.02.012

Aristilde, L., Marichal, C., Miéhé-Brendlé, J., Lanson, B., and Charlet, L. (2010). Interactions of oxytetracycline with a smectite clay: a spectroscopic study with molecular simulations. Environ. Sci. Technol. 44, 7839-7845. doi: $10.1021 /$ es102136y

Armand, M., Grugeon, S., Vezin, H., Laruelle, S., Ribière, P., Poizot, P., et al. (2009). Conjugated dicarboxylate anodes for Li-ion batteries. Nat. Mater. 8, 120-125. doi: $10.1038 /$ nmat 2372

Auerbach, E. A., Seyfried, E. E., and McMahon, K. D. (2007). Tetracycline resistance genes in activated sludge wastewater treatment plants. Water Res. 41, 1143-1151. doi: 10.1016/j.watres.2006.11.04

Duan, J., Hou, H., Liu, X., Liu, S., Liao, Q., and Yao, Y. (2016). High performance $\mathrm{PPO} / \mathrm{Ti}^{3+} / \mathrm{TiO}_{2} \mathrm{NT}$ membrane/electrode for lithium ion battery. Ceram. Int. 42, 16611-16618. doi: 10.1016/j.ceramint.2016.07.082

Elizabeth, I., Singh, B. P., Trikha, S., and Gopukumar, S. (2016). Bioderived hierarchically macro-meso-micro porous carbon anode for lithium/sodium ion batteries. J. Power Sources 329 (Supplement C), 412-421. doi: 10.1016/j.jpowsour.2016.08.106

Han, S. W., Jung, D. W., Jeong, J. H., and Oh, E. S. (2014). Effect of pyrolysis temperature on carbon obtained from green tea biomass for superior lithium ion battery anodes. Chem. Eng. J. 254, 597-604. doi: 10.1016/j.cej.2014. 06.021

Harja, M., and Ciobanu, G. (2018). Studies on adsorption of oxytetracycline from aqueous solutions onto hydroxyapatite. Sci. Total Environ. 628, 36-43. doi: 10.1016/j.scitotenv.2018.02.027

Hou, H., Dai, Z., Liu, X., Yao, Y., Liao, Q., Yu, C., et al. (2018a). Reutilization of the expired tetracycline for lithium ion battery anode. Sci. Total Environ. 630, 495-501. doi: 10.1016/j.scitotenv.2018.02.126

Hou, H., Yu, C., Liu, X., Yao, Y., Liao, Q., Dai, Z., et al. (2018b). Waste-loofahderived carbon micro/nano particles for lithium ion battery anode. Surf. Innovations 6, 159-166. doi: 10.1680/jsuin.17.00068

Huang, X. D., Zhang, F., Gan, X. F., Huang, Q. A., Yang, J. Z., Lai, P. T., et al. (2018). Electrochemical characteristics of amorphous silicon carbide film as a lithium-ion battery anode. RSC Adv.8, 5189-5196. doi: 10.1039/ c7ra12463e

Ji, L., Lin, Z., Alcoutlabi, M., and Zhang, X. (2011). Recent developments in nanostructured anode materials for rechargeable lithium-ion batteries. Energy Environ. Sci. 4, 2682-2699. doi: 10.1039/c0ee00699h

Ji, L., Meduri, P., Agubra, V., Xiao, X., and Alcoutlabi, M. (2016). Graphenebased nanocomposites for energy storage. Adv. Energy. Mater. 6:1502195. doi: 10.1002/aenm.201502159

Jin, X., Qiu, S., Wu, K., Jia, M., Xiong, F., Gu, C., et al. (2016). The effect of $\mathrm{Cu}^{2+}$ chelation on the direct photolysis of oxytetracycline: a study assisted by spectroscopy analysis and DFT calculation. Environ. Pollut. 214, 831-839. doi: 10.1016/j.envpol.2016.04.084

Kummerer, K. (2009). Antibiotics in the aquatic environment - a review - part I. Chemosphere 75, 417-434. doi: 10.1016/j.chemosphere.2008. 11.086

Liang, Y., Tao, Z., and Chen, J. (2012). Organic electrode materials for rechargeable lithium batteries. Adv. Energy Mater. 2, 742-769. doi: 10.1002/aenm. 201100795

Liu, Y., Xue, J., Zheng, T., and Dahn, J. (1996). Mechanism of lithium insertion in hard carbons prepared by pyrolysis of epoxy resins. Carbon N. Y. 34, 193-200. doi: 10.1016/0008-6223(96)00177-7
Mahamallik, P., Saha, S., and Pal, A. (2015). Tetracycline degradation in aquatic environment by highly porous $\mathrm{MnO}_{2}$ nanosheet assembly. Chem. Eng. J. 276, 155-165. doi: 10.1016/j.cej.2015.04.064

Matsubara, E., Lala, S., and Rosolen, J. (2010). Lithium storage into carbonaceous materials obtained from sugarcane bagasse. J. Braz. Chem. Soc. 21, 1877-1884. doi: 10.1590/S0103-50532010001000012

Orellana, S., Soto, C., and Toral, M. I. (2010). UV-vis, IR and $1 \mathrm{H}$ NMR spectroscopic studies and characterization of ionic-pair crystal violet-oxytetracycline. Spectrochim. Acta Part A 75, 437-443. doi: 10.1016/j.saa.2009.11.002

Renault, S., Brandell, D., Guatafsson, T., and Edström, K. (2013). Improving the electrochemical performance of organic Li-ion battery electrodes. Chem. Commun. 49, 1945-1947. doi: 10.1039/c3cc39065a

Schon, T. B., Mcallister, B. T., Li, P. F., and Seferos, D. S. (2016). The rise of organic electrode materials for energy storage. Chem. Soc. Rev. 45, 6345-6404. doi: 10.1039/C6CS00173D

Stezowski, J. J. (1976). Chemical-structural properties of tetracycline derivaties. 1. Molecular structure and conformation of the free base derivatives. J. Am. Chem. Soc. 98, 6012-6018. doi: 10.1021/ja00435a 039

Sullivan, B. A., Vance, C. C., Gentry, T. J., and Karthikeyan, R. (2017). Effects of chlorination and ultraviolet light on environmental tetracyclineresistant bacteria and tet(W) in water. J. Environ. Chem. Eng. 5, 777-784. doi: 10.1016/j.jece.2016.12.052

Sun, X., Shao, C., Zhang, F., Li, Y., Wu, Q., and Yang, Y. (2018). SiC nanofibers as long-life lithium-ion battery anode materials. Front. Chem. 6:166. doi: 10.3389 /fchem. 2018.00166

Sun, Y., Liu, N., and Cui, Y. (2016). Promises and challenges of nanomaterials for lithium-based rechargeable batteries. Nat. Energy 1:16071. doi: 10.1038/NENERGY.2016.71

Tang, K., White, R. J., Mu, X., Titirici, M. M., Van Aken, P. A., and Maier, J. (2012). Hollow carbon nanospheres with a high rate capability for lithium-based batteries. ChemSusChem 5, 400-403. doi: 10.1002/cssc.201100609

Titirici, M. M., and Antonietti, M. (2009). Chemistry and materials options of sustainable carbon materials made by hydrothermal carbonization. Chem. Soc. Rev. 39, 103-116. doi: 10.1039/ B819318P

Toro, R., Diaz de Delgado, G., Bahsas, A., and Delgado, J. M. (2007). The presence of polymorphism in oxytetracycline hydrochloride shown by X-ray powder diffraction techniques. Z. Kristallogr. Suppl. 26, 563-568. doi: 10.1524/zksu.2007.2007.suppl_26.563

Wang, H., Che, B., Duan, A., Mao, J., Dahlgren, R. A., Zhang, M., et al. (2014). Toxicity evaluation of beta-diketone antibiotics on the development of embryo-larval zebrafish (danio rerio). Environ. Toxicol. 29, 1134-1146. doi: $10.1002 /$ tox. 21843

Wang, L., Schnepp, Z., and Titirici, M. (2013a). Rice husk-derived carbon anodes for lithium ion batteries. J. Mater.Chem. A 1, 5269-5273. doi: $10.1039 / \mathrm{c} 3$ ta10650k

Wang, S., Wang, L., Zhang, K., Zhu, Z., Tao, Z., and Chen, J. (2013b). Organic $\mathrm{Li}_{4} \mathrm{C}_{8} \mathrm{H}_{2} \mathrm{O}_{6}$ nanosheets for lithium-ion batteries. Nano Lett. 13, 4404-4409. doi: $10.1021 / \mathrm{nl} 402239 \mathrm{p}$

Wang, Z., Du, Y., Yang, C., Liu, X., Zhang, J., Li, E., et al. (2017). Occurrence and ecological hazard assessment of selected antibiotics in the surface waters in and around lake Honghu, China. Sci. Total Environ. 609, 1423-1432. doi: 10.1016/j.scitotenv.2017.08.009

Wu, J., Zuo, L., Song, Y., Chen, Y., Zhou, R., Chen, S., et al. (2016). Preparation of biomass-derived hierarchically porous carbon $/ \mathrm{Co}_{3} \mathrm{O}_{4}$ nanocomposites as anode materials for lithium-ion batteries. J. Alloys Compd. 656, 745-752. doi: $10.1016 /$ j.jallcom.2015.10.063

Xiong, Y., Harb, M., and Hong, P. Y. (2017). Performance and microbial community variations of anaerobic digesters under increasing tetracycline concentrations. Appl. Microbiol. Biotechnol. 101, 5505-5517. doi: 10.1007/s00253-017-8253-1

Yan, C., Yang, Y., Zhou, J., Liu, M., Nie, M., Shi, H., et al. (2013). Antibiotics in the surface water of the Yangtze estuary: occurrence, distribution and risk assessment. Environ. Pollut. 175, 22-29. doi: 10.1016/j.envpol.2012.12.008

Zhang, H., Deng, Q., Zhou, A., Liu, X., and Li, J. (2014). Porous $\mathrm{Li}_{2} \mathrm{C}_{8} \mathrm{H}_{4} \mathrm{O}_{4}$ coated with $\mathrm{N}$-doped carbon by using CVD as an anode material for Li-ion batteries. J. Mater. Chem. A 2, 5696-5702. doi: 10.1039/c3ta14720g 
Zhang, M., Yang, H., Liu, Y., Sun, X., Zhang, D., and Xue, D. (2012). Hydrophobic precipitation of carbonaceous spheres from fructose by a hydrothermal process. Carbon N. Y. 50, 2155-2161. doi: 10.1016/j.carbon.2012.01.024

Zuniga, L., Agubra, V., Flores, D., Campos, H., Villareal, J., and Alcoutlabi, M. (2016). Multichannel hollow structure for improved electrochemical performance of $\mathrm{TiO}_{2} /$ Carbon composite nanofibers as anodes for lithium ion batteries. J. Alloys Compd. 686, 733-743. doi: 10.1016/j.jallcom. 2016.06.089

Zuo, X., Zhu, J., Müller-Buschbaum, P., and Cheng, Y. (2017). Silicon based lithium-ion battery anodes: a chronicle perspective review. Nano Energy 31, 113-143. doi: 10.1016/j.nanoen.2016.11.013
Conflict of Interest Statement: The authors declare that the research was conducted in the absence of any commercial or financial relationships that could be construed as a potential conflict of interest.

Copyright (c) 2019 Hou, Dai, Liu, Yao, Yu and Li. This is an open-access article distributed under the terms of the Creative Commons Attribution License (CC BY). The use, distribution or reproduction in other forums is permitted, provided the original author(s) and the copyright owner(s) are credited and that the original publication in this journal is cited, in accordance with accepted academic practice. No use, distribution or reproduction is permitted which does not comply with these terms. 